\title{
Interprofessional education program for medical and nursing students: interprofessional versus uniprofessional
}

\author{
Yon Chul Park ${ }^{1,2}$ and Kyung Hye Park ${ }^{1,3}$ \\ Departments of ${ }^{1}$ Medical Education, ${ }^{2}$ Family Medicine, and ${ }^{3}$ Emergency Medicine, Yonsei University Wonju College \\ of Medicine, Wonju, Korea
}

Purpose: This study determined the effects of interprofessional education (IPE) on self-efficacy and attitude by comparing an interprofessional (IP) group of medical students (MSs) and nursing students (NSs) and a uniprofessional (UP) group of MSs.

Methods: An experimental IP group consisting of 49 MSs and 62 NSs was selected, alongside a UP control group of 48 other MSs. The groups participated in a class titled "Team Communication and Interprofessional Collaboration." A sub-analysis of the two groups' professions was also conducted. The groups participated in the same lesson separately, with a week's interval. The Interprofessional Attitudes Scale (IPAS) and the Self-Efficacy Perception for Interprofessional Experiential Learning (SEIEL) scale were used before and after the class to compare changes in reports of self-efficacy and attitudes in both groups. Students' responses to learning experiences and satisfaction were also evaluated.

Results: IPAS and SEIEL values increased after the class for MSs in both groups; there were no differences between the groups. IPAS and SEIEL values increased after the class in MSs and NSs in the IP group, and the effect size for IPAS was larger for IP-group NSs than for IP-group MSs. Satisfaction scores exceeded 3.70 in both groups.

Conclusion: The UP group showed similar IPE effects as the IP group, as measured by SEIEL and IPAS, in a single IPE program that used role-play and case-based discussion. However, it would be desirable for the UP group to interact with other professions to improve understanding and experience.

Key Words: Self efficacy, Attitude, Interprofessional education, Team communication, Nursing students, Medical students

\section{Introduction}

Teamwork has always been essential in clinical environments; therefore, interprofessional education (IPE) has become an important factor in medical education in recent years. Teamwork is increasingly important because medical practice has become more complex and specialized than ever before; disease patterns have changed from, for example, a simple communicable disease to complex multi-morbidity chronic diseases. Furthermore, all healthcare professionals have their own expertise and skills and continuously communicate and collaborate among themselves, with the common goal of patient care. This is why teamwork is important in healthcare. Furthermore, no medical practice can be performed by one healthcare professional alone. During treatment, a single
Received: November 19, 2020 • Revised: January 11, $2021 \bullet$ Accepted: February 5, 2021 Corresponding Author: Kyung Hye Park (https://orcid.org/0000-0002-5901-6088)

Department of Medical Education, Yonsei University Wonju College of Medicine, 20 Ilsan-ro, Wonju 26426, Korea

Tel: +82.33.741.0242 Fax: +82.33.742.5034 email: erdoc@yonsei.ac.kr
Korean J Med Educ 2021 Mar; 33(1): 1-10 https://doi.org/10.3946/kjme.2021.182 eISSN: 2005-7288

(C) The Korean Society of Medical Education. All rights reserved. This is an open-access article distributed under the terms of the Creative Commons Attribution Non-Commercial License (http:// creativecommons.org/licenses/by-nc/3.0/), which permits unrestricted non-commercial use, distribution, and reproduction in any medium, provided the original work is properly cited. 
patient meets doctors, nurses, medical technologists, and even administrators in different sections of the healthcare system. The more specialized a healthcare system is, the more steps a patient experiences. Therefore, the World Health Organization (WHO) has proclaimed the importance of IPE since 1988 for these exact reasons [1].

When healthcare-associated students become practitioners, they become acculturated into their own professional identity, which could lead to barriers to collaboration in a clinical environment [2]. Therefore, teamwork and interprofessionalism should be taught to healthcare students as part of their undergraduate education. Most undergraduate IPE classes target medical students (MSs) and nursing students (NSs) via various types of classes and lessons. The effects of IPE on MSs and NSs are well-known, and to date, similar results have been achieved, regardless of the teaching method used. IPE contributes to students identifying their own shortcomings and recognizing the value of their colleagues' approaches and to diminishing stereotypes and hierarchies. Existing studies have shown improvements in IP perception and clinical reasoning skills in a student-run free clinic, and a positive effect on students' mutual appreciation in problem-based learning [3,4]. In simulation-based training, IP students gained enhanced understanding of other professionals' work, communication, teamwork and leadership, and self-efficacy as better team leaders [5-7]. IPE has also been shown to enhance the development of interprofessional thinking and patient-centered care, acquiring shared knowledge, and promoting mutual understanding [8-10].

Several researchers have examined uniprofessional (UP) group learning, believing that evidence of IPE's effectiveness was still lacking because coordinating and harmonizing the two professions' curricula is the most prominent difficulty in IPE [11]. In a study of Račić et al. [12], the IP group consisted of MSs, NSs, and dental students, and three UP groups consisted of students of each profession. All groups showed higher follow-up scores on diabetes knowledge than baseline scores; however, the IP group's posttest score was higher than those of the UP groups. Additionally, the IP group had a more positive self-assessment of communication and teamwork skills [12]. In a Taiwanese study, the IP group (MSs and NSs) gained higher interprofessional communication and collaboration than the UP group (MSs) in problem-based learning on clinical ethics [13]. Berger et al. [14] used an IP seminar to compare an IP group of undergraduate medical and other healthcare students and a UP group (undergraduate MSs) in German medical education. The IP group showed a more positive reaction and higher mean scores on self-reported knowledge gains in group dynamics. However, scores for communication and teamwork and IP learning increased in both groups. The UP group showed improvement in medical knowledge but only some improvement in communication and teamwork skills. Overall, these aforementioned studies have found UP groups shows equal achievement in knowledge and some achievement in communication and teamwork skill, and in IP group, it shows better communication and teamwork skill achievement.

IPE requires active learner participation, interaction, and active exchanges between learners from different health professions to improve IP collaboration [15]. Although students from more than one healthcare profession must interact and learn together for education to be defined as IPE, interaction in a single-profession group seems effective to some extent. Because the IPE concept is still underdeveloped in the context of undergraduate medical education in Korea, we examined IPE's effectiveness in Korean undergraduate medical education. Specifically, we examined IPE's effects on 
self-efficacy and attitude by comparing MSs and NSs in an IP group, with a UP group of MSs as a control. Additionally, IPE satisfaction and reactions were investigated.

\section{Methods}

\section{Study population and IPE lesson}

This quasi-experimental before and after comparison study recruited 159 participants from among fifth-year MSs and fourth-year NSs at Wonju College of Medicine, Yonsei University in Korea in May 2019. The medical school has a 6-year program consisting of a 2-year premedical phase, a 2-year pre-clinical medical phase, and a 2-year clinical clerkship phase. The fifth-year MSs were in the first semester of their clinical clerkship phase. They were semi-randomly divided into two groups: IP or UP. The NSs were in the third semester and the fourth year of their 4-year bachelor program. The IP group consisted of 49 MSs and 62 NSs, whereas the UP group consisted of $48 \mathrm{MSs}$. As this IPE was part of the formal curriculum, all fifth-year MSs and fourth-year NSs participated. The IP group was divided into small groups consisting of three MSs and three to four NSs; in contrast, the UP group was divided into small groups consisting of only six MSs. The schedule was discussed with a nursing department professor to enable the students to gather together at the same time.

Finally, MSs took IPE as part of the "Patient Safety" course of the regular curriculum and the NSs as part of the "Health Communication" course. The IP group received the lesson first, and the UP group received the same lesson after 1 week. "Team Communication and Interprofessional Collaboration" was chosen as the IPE topic.
IPE was conducted as flipped learning. Before the in-class activity, a 30-minute online lecture was provided to all students using the learning management system platform, Yonsei Creative Education Community (YSCEC, https://yscec.yonsei.ac.kr). This lecture was created by the researcher and was based on "being an effective team player" from the WHO Patient Safety Curriculum Guide for Medical Schools [16]. The in-class activity consisted of interactive theater and a group discussion. Interactive theater is a useful educational strategy to encourage behavior change in medical communication and conflict resolution [17].

The role-play scenario was developed by the researcher (emergency department physician) and reviewed by one emergency department head nurse and one emergency department resident to improve accuracy and relatability. The scenario depicted a medical error related to blood transfusion that occurred due to poor communication between medical staff and poor patient identification. After the students read the scenario, they engaged in role-play at the front of the classroom. The researcher stopped the role-play if necessary to ask students to express their feelings on the situation and the other students' positions; participants were also allowed to change lines if they wanted. After modifying the given scenario to prevent medical error as group activity, some of the students presented their role-play in front of the others. All students practiced reporting the situation, information sharing between medical staff, and using team communication techniques (call-out, checkback, SBAR [Situation Background Assessment Recommendation], I-PASS the BATON [Introduction, Patient, Assessment, Situation, Safety concerns, Background, Actions, Timing, Ownership, and Next]) (Fig. 1).

\section{Sample scenario}

It is Monday morning, and the emergency room (ER) 
is busy. At virtually the same time, two female patients, named "Young" and "Kyoung," respectively, enter the ER. Young reports vomiting a lot of blood and is hypotensive. Kyoung was diagnosed with appendicitis at a local community hospital and transferred to the ER for surgery. The ER resident orders blood tests, including $\mathrm{A} / \mathrm{B} / \mathrm{O}$ typing and cross matching for a transfusion for Young. They order the same blood tests in preparation for Kyoung's appendectomy. A novice nurse draws blood from the two patients and prepares barcode stickers and sample tubes for the two patients at the same time. She checks each patient's name, but the names sound very similar, and the barcode stickers are switched. After about an hour, a packed RBC is prepared for Young, and an intern asks Young about her blood type. Young answers that her blood is type B; however, the intern has type $A B$ readied for the transfusion and assumes that Young is wrong about her blood type. The intern then starts the blood transfusion to Young. The scenario ends.

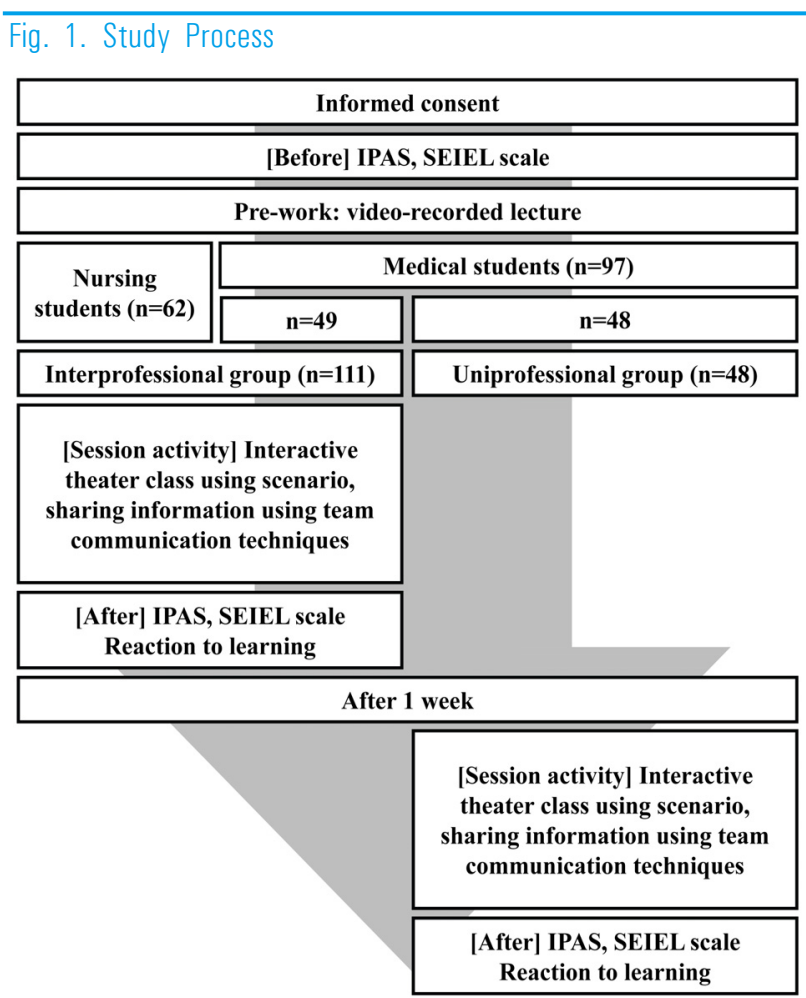

IPAS: Interprofessional Attitudes Scale, SEIEL: Self-efficacy Perception for Interprofessional Experiential Learning.

\section{Data collection}

Students' satisfaction (5-point Likert scale) and their reaction to the learning experiences (what they liked and what they thought could improve the class) were immediately evaluated after class as the Kirkpatrick level 1 outcome. To appraise potential changes in attitude, the Interprofessional Attitudes Scale (IPAS) and the Self-Efficacy Perception for Interprofessional Experiential Learning (SEIEL) scale were used before and after the class as the Kirkpatrick level 2 outcome [18].

IPAS measures attitudes toward other healthcare professions; we used the validated Korean version based on the original version developed by Norris et al. [19]. The Korean version of the IPAS consists of 20 items that are scored from 1-5; the instrument has good reliability (Cronbach's $\alpha=0.929$ ) [20]. The higher the total score, the better the participant's attitude toward other healthcare professions. SEIEL measures the self-efficacy of interprofessional learning. We used the validated Korean version based on the original version developed by Mann et al. [21]. The Korean version of the SEIEL scale consists of 11 items that have good reliability (Cronbach's $\alpha$ =0.932). The higher the total score, the higher the participant's self-efficacy [22]. The scale questionnaires were distributed online via a survey link one week before the class. When the class was finished, both groups' students again completed the IPAS and SEIEL questionnaires and the satisfaction questionnaire (Fig. 1).

\section{Data analysis}

Data were collected using the online survey system SurveyMonkey（https://ko.surveymonkey.com). Cronbach's $\alpha$ was used to verify the internal consistency reliability of the IPAS and SEIEL scales. A paired t-test was used to compare IPAS and SEIEL scores before and after class, and Cohen's d was calculated as effect size. 
Student $\mathrm{t}$-test was used to compare IPAS, SEIEL, score difference between IPAS and SEIEL, and satisfaction scores between the groups. IBM SPSS ver. 23.0 (IBM Corp., Armonk, USA) software was used for the analyses; significance was set at $\mathrm{p}<0.05$. Narrative type reactions were classified using content analysis by one author (K.H.P.) and then check by another author (Y.C.P.). Similar content was grouped together to indicate the frequency of appearance.

\section{Ethical considerations}

This study was approved by the Institutional Review Board of Yonsei University Wonju Christian Severance Hospital (IRB approval no., CR318144). All participants were informed of the purpose of this study and that the data would be collected anonymously and treated confidentially. Only profession (medical/nurse) and telephone numbers were collected for corresponding before and after class. Written informed consent was obtained from all students.

\section{Results}

Ninety-seven MSs and 62 NSs participated in the class
(IP group, 49 MSs and 62 NSs; UP group, 48 MSs). Of the 159 students, 158 students completed the IPAS and SEIEL before the class, and 143 students responded after the class. Finally, 136 students who responded to both surveys were included in the analysis. The average age was 23.13 years in the IP group and 23.80 in the UP group; no significant difference was found. MSs had an average age of 24.13 years and NSs 22.41 years (Table 1). Cronbach's $\alpha$ showed high internal consistency. Cronbach's $\alpha$ for IPAS before the class was 0.927 and 0.955 after the class. Cronbach's $\alpha$ for SEIEL before the class was 0.956 and 0.975 after the class.

The IPAS and SEIEL scores before and after the class were compared by groups. The scores for both the IPAS and SEIEL scales significantly increased after the class in all student groups. The IPAS increase differed slightly for NSs and MSs in the IP group. The effect size as measured by Cohen's d was about 0.6 in NSs, but that of IP-group MSs was small, 0.142 (Table 2). Regarding MSs, both groups' IPAS and SEIEL scores increased post-class (Table 2). The effect size of IPAS for IP-group MSs was relatively smaller than for those in the UP group (Table 2), but IPAS between the IP and UP groups were not different (Table 3). There was also no difference in SEIEL scores between the IP and UP

\begin{tabular}{|c|c|c|c|}
\hline Groups & Medical students $(n=38)$ & Nursing students $(n=54)$ & Total \\
\hline \multicolumn{4}{|l|}{ Interprofessional group } \\
\hline Male & 28 & 7 & 35 \\
\hline Female & 10 & 47 & 57 \\
\hline Age (yr) & $24.13 \pm 1.99^{a l}$ & $22.41 \pm 1.91^{\mathrm{a}}$ & $23.13 \pm 2.11$ \\
\hline Total & 38 & 54 & 92 \\
\hline \multicolumn{4}{|l|}{ Uniprofessional group } \\
\hline Male & 29 & - & \\
\hline Female & 15 & - & \\
\hline Age (yr) & $23.80 \pm 1.83$ & - & \\
\hline Total & 44 & - & \\
\hline
\end{tabular}

Data are presented as number or mean \pm standard deviation.

IP: Interprofessional, UP: Uniprofessional.

a)-value $<0.001$ for t-test of age between medical students and nursing students in interprofessional group. 
Yon Chul Park and Kyung Hye Park: Interprofessional vs. uniprofessional education

\begin{tabular}{llllrc}
\hline \multicolumn{5}{l}{ Table 2. The Program Effects by Paired Comparisons of IPAS and SEIEL Scores before and after the Class } \\
\hline \multicolumn{1}{c}{ Group } & Variable & Before & After & p-value & Cohen's d \\
\hline IP group ( $\mathrm{n}=92)$ & IPAS & $80.32 \pm 9.40$ & $85.01 \pm 11.51$ & $<0.001$ & 0.418 \\
& SEIEL & $73.22 \pm 14.93$ & $83.97 \pm 17.24$ & $<0.001$ & 0.686 \\
Medical students in IP group (n=38) & IPAS & $82.47 \pm 8.80$ & $84.18 \pm 12.15$ & 0.018 & 0.142 \\
& SEIEL & $72.82 \pm 18.20$ & $84.32 \pm 17.88$ & $<0.001$ & 0.789 \\
Nursing students in IP group (n=54) & IPAS & $78.80 \pm 9.59$ & $85.59 \pm 11.12$ & $<0.001$ & 0.663 \\
& SEIEL & $73.50 \pm 2.31$ & $82.72 \pm 16.93$ & 0.003 & 0.619 \\
UP group ( $\mathrm{n}=44)$ & IPAS & $83.14 \pm 9.87$ & $86.93 \pm 10.72$ & 0.001 & 0.528 \\
& SEIEL & $78.14 \pm 17.93$ & $87.63 \pm 18.65$ & $<0.001$ & 0.785 \\
\hline
\end{tabular}

Data are presented as mean \pm standard deviation.

IPAS: Interprofessional Attitudes Scale, SEIEL: Self-efficacy Perception for Interprofessional Experiential Learning, IP: Interprofessional, UP: Uniprofessional.

\begin{tabular}{lccc}
\hline \multicolumn{1}{c}{ Table 3. Comparative Analysis of Interprofessional Education between $I P$ Group and UP Group in Medical Students } \\
\hline \multicolumn{1}{c}{ Variable } & IP group $(\mathrm{n}=38)$ & UP group $(\mathrm{n}=44)$ & p-value \\
\hline IPAS & & & \\
Before & $82.47 \pm 8.80$ & $83.14 \pm 9.87$ & 0.801 \\
After & $84.18 \pm 12.15$ & $86.93 \pm 10.72$ & 0.280 \\
SEIEL & & & \\
Before & $72.82 \pm 18.20$ & $78.14 \pm 17.93$ & 0.216 \\
After & $84.32 \pm 17.88$ & $87.63 \pm 18.65$ & 0.419 \\
\hline
\end{tabular}

Data are presented as mean \pm standard deviation.

IP: Interprofessional, UP: Uniprofessional, IPAS: Interprofessional Attitudes Scale, SEIEL: Self-efficacy Perception for Interprofessional Experiential Learning.

\begin{tabular}{lcc}
\hline \multicolumn{1}{c}{ Table 4. Comparison of the Satisfaction Scores } & & \\
\hline \multicolumn{1}{c}{ Groups } & Score & p-value \\
\hline All $(\mathrm{n}=136)$ & $3.84 \pm 0.90$ & 0.447 \\
IP group & & \\
Medical students $(\mathrm{n}=39)$ & $3.72 \pm 0.94$ & \\
$\quad$ Nursing students $(\mathrm{n}=53)$ & $3.87 \pm 0.95$ & \\
Medical students & & \\
IP group $(\mathrm{n}=38)$ & $3.72 \pm 0.94$ \\
UP group $(\mathrm{n}=44)$ & $3.91 \pm 0.80$ & \\
\hline
\end{tabular}

Data are presented as mean \pm standard deviation.

IP: Interprofessional, UP: Uniprofessional.

groups (Table 3).

The mean and standard deviation of the satisfaction score of all students was $3.84 \pm 0.90$. There were no differences between the IP and UP groups for MSs or between MSs and NSs in the IP group, with scores ranging between 3.72-3.91 (Table 4).

Content analysis was conducted. In the IP group, the most common opinions were "I am interested in a class with counterpart students," followed by including role-play and case-based discussion in the learning method. In the UP group, comments about interaction were not collected, but they liked the learning methods. Regarding what they think would improve the class, IP-group MSs and NSs cited lack of teamwork formation 
Table 5. Summary of Narrative Data of Reaction to the Class

\begin{tabular}{|c|c|c|}
\hline Category & Group & Contents (no. of frequency) \\
\hline \multirow[t]{3}{*}{ What they liked } & IP group: medical students & $\begin{array}{l}\text { Interested in class with nursing students (20) } \\
\text { Case-based discussion and making the presentation (7) } \\
\text { A new way of teaching and learning (7) } \\
\text { Role-play (4) } \\
\text { Deep understanding of interprofessionalism (1) }\end{array}$ \\
\hline & IP group: nursing students & $\begin{array}{l}\text { Interested in class with medical students (19) } \\
\text { Role-play (15) } \\
\text { Case-based discussion and making the presentation (10) } \\
\text { Class contents (3) }\end{array}$ \\
\hline & UP group & $\begin{array}{l}\text { Role-play and revising scenario (21) } \\
\text { Case-based discussion and making the presentation (10) } \\
\text { Class contents (7) }\end{array}$ \\
\hline \multirow[t]{3}{*}{$\begin{array}{l}\text { What they think would } \\
\text { improve the class }\end{array}$} & IP group: medical students & $\begin{array}{l}\text { Lack of teamwork formation time (8) } \\
\text { Lack of class time (8) }\end{array}$ \\
\hline & IP group: nursing students & $\begin{array}{l}\text { More active rather than passive learning (10) } \\
\text { Lack of class time (8) } \\
\text { Lack of teamwork formation time (7) } \\
\text { Need scenarios of various cases }(5)\end{array}$ \\
\hline & UP group & $\begin{array}{l}\text { Need scenarios of various cases }(9) \\
\text { Want to have a class with nursing students }(6) \\
\text { Uncomfortable making the presentation }(5)\end{array}$ \\
\hline
\end{tabular}

IP: Interprofessional, UP: Uniprofessional.for Interprofessional Experiential Learning.

time and class time. In particular, NSs wanted more active learning in the class. UP-group students said that more scenarios of various cases were needed, and they wanted to have a class with NSs (Table 5).

\section{Discussion}

This study measured attitude and self-efficacy as well as participants' reactions to IPE in the IP and UP groups before and after IPE. Regardless of profession (medical/nurse) or group, all scores increased after IPE. This improvement is not surprising, considering previous studies showed improved outcomes after IPE, regardless of profession and learning method [3-7].

We observed noticeable changes in the IPAS scores of NSs after IPE, showing a large effect size, but not in MSs' scores. Previous studies confirmed that fourth-year
MSs do not notably change their bias regarding other occupations after IPE. For MSs, there was no change from pretest to posttest in positive stereotypes of nurses. However, nurses' positive stereotypes about doctors increased from pretest to posttest [8]. In our study, part of the reason for the small effect size in IPAS for IP-group MSs is that they were already in their fifth year of school and older than NSs, so changing their stereotypes would be difficult. "Hidden curriculum" is the one of the contributing factors to uniprofessional identity formation, and they had been exposed to a hidden curriculum for one year longer than the NSs. Further there is a definite difference in formal as well as hidden curricula between MSs and NSs. In other words, the formation of UP identity would have become more robust through role-modeling and learning with residents or professors during clinical clerkship. Khalili et al. [23] reported that if IPE is conducted with UP 
identity already formed, IP identity is developed as (1) breaking down barriers, (2) IP role learning and IP collaboration, and (3) dual identity development. Finally, professional and IP favoritism, willingness, and confidence in an IP collaborative person-centered practice are formed [23]. If students from more than one profession learn together often, they can attain stage three (dual identity development). However, if uniprofessional students learn interprofessional communication, they can partially break down barriers and experience interprofessional role learning. Another possible reason for the small change is that IP-group MSs' baseline IPAS score was higher than that of the NSs, although as there was no statistical difference in the baseline IPAS.

Considering MSs, there was no difference in IPAS and SEIEL scores between IP and UP groups before and after the class. Thus, MSs obtained coterminous IPE effects, even though they were in the UP group and therefore subject to obstacles, such as absence of other healthcareassociated students with whom to interact. Previous studies comparing IP and UP groups reported some positive effects in the UP group when the same program was used [12,14]. In short, presenting IPE to an IP group is better than to a UP group, but presenting IPE to a UP group is better than providing no such education.

Regarding satisfaction scores, there were no differences between groups or between professions (medical/ nurse). IP-group students found it interesting to learn with their counterparts and stated that they wanted more time for teamwork building and class. The examples of IP group students' statement 'Interested in class with the counterpart students.' are that they had a better understanding of interprofessionalism and that they were amazed at the many fresh opinions expressed by NSs. Some said that it was their first time talking to someone of the other profession. This was surprising because the students studied at the same campus and conducted their clinical clerkships in the same hospital. Some MSs or NSs in our college even shared the same dormitory and participated together in club activities. As UP-group students did not meet NSs, they said it would be more interesting and that they would understand the topic better if they interacted with NSs during IPE. Although the content and method of instruction are interesting, it seems better to meet and interact with students from other majors to achieve the true outcome of IPE.

Although IPE should comprise active participation and interaction among students from more than one health profession [15], interaction in a UP MS group seems to have a similar effect as in an IP group when measured by IPAS and SEIEL. Similar to our study, an existing study of only MSs found that there was a competency increase in interpersonal communication, as measured by the Global Interpersonal Communication Competence Scale [24]. Nevertheless, when analyzing the narrative response, it seems ideal to implement IPE if possible because the UP group wanted to interact with other students, and the IP group were satisfied with the interaction.

This study has several limitations, including small population size, the short duration of the intervention, and by its cross-sectional design. Repeating IPE over time is necessary to consolidate competence acquisition and to encourage teambuilding. As there was no UP NS group in this study, it was impossible to compare the IP NS group with a UP NS group. Social desirability bias might be an issue in the survey of attitudes and self-efficacy; however, the narrative reactions collected anonymously appeared straightforward. Content analysis is not through interviews, but is simply an analysis of the narrative descriptions, so that validity and reliability would be limited compared to qualitative research.

In a single IPE program using role-play and 
case-based discussion, the UP group experienced similar IPE effects as the IP group, based on the SEIEL and IPAS scores. However, it would be desirable for MSs to interact with NSs, contingent upon curriculum coordination and support from the school system. NSs' attitudes toward interprofessionalism showed a more positive change than those of MSs. However, factors affecting the different effect sizes should be investigated further.

\section{ORCID:}

Yon Chul Park: https://orcid.org/0000-0002-1787-0884; Kyung Hye Park: https://orcid.org/0000-0002-5901-6088

Acknowledgements: I would like to express my heartfelt appreciation to professor Young Mi Lim from the Department of Nursing, Yonsei University, Wonju College of Medicine, for cooperating with me on the successful IPE.

Funding: This research was supported by the National Research Foundation of Korea (NRF), grant funded by the Korea government (MSIP: Ministry of Science, ICT \& Future Planning; No. 2017R1C1B5074565).

Conflicts of interest: No potential conflict of interest relevant to this article was reported.

Author contributions: Conception or design of the work: KHP; data collection, data analysis and interpretation: YCP and KHP; drafting the article: YCP; critical revision of the article: KHP; and final approval of the version to be published: YCP and KHP.

\section{References}

1. World Health Organization. Learning together to work together for health: report of a WHO Study Group on Multiprofessional Education of Health Personnel: the
Team Approach [meeting held in Geneva from 12 to 16 October 1987]. https://apps.who.int/iris/handle/10665/3741 l. Published 1988. Accessed November 20, 2019.

2. Hall P. Interprofessional teamwork: professional cultures as barriers. J Interprof Care. 2005;19 Suppl 1:188-196.

3. Seif G, Coker-Bolt P, Kraft S, Gonsalves W, Simpson K, Johnson E. The development of clinical reasoning and interprofessional behaviors: service-learning at a studentrun free clinic. J Interprof Care. 2014;28(6):559-564.

4. Dreier-Wolfgramm A, Homeyer S, Oppermann RF, Hoffmann W. A model of interprofessional problembased learning for medical and nursing students: implementation, evaluation and implications for future implementation. GMS J Med Educ. 2018;35(1):Docl3.

5. Hobgood C, Sherwood G, Frush K, et al. Teamwork training with nursing and medical students: does the method matter?: results of an interinstitutional, interdisciplinary collaboration. Qual Saf Health Care. 2010; 19(6):e25.

6. Eisenmann D, Stroben F, Gerken JD, Exadaktylos AK, Machner M, Hautz WE. Interprofessional emergency training leads to changes in the workplace. West J Emerg Med. 2018;19(1):185-192.

7. Jakobsen RB, Gran SF, Grimsmo B, et al. Examining participant perceptions of an interprofessional simulationbased trauma team training for medical and nursing students. J Interprof Care. 2018;32(1):80-88.

8. Lockeman KS, Appelbaum NP, Dow AW, et al. The effect of an interprofessional simulation-based education program on perceptions and stereotypes of nursing and medical students: a quasi-experimental study. Nurse Educ Today. 2017;58:32-37.

9. Kara A, DeMeester D, Lazo L, Cook E, Hendricks S. An interprofessional patient assessment involving medical and nursing students: a qualitative study. J Interprof Care. 2018;32(4):513-516.

10. Leathers JS, Davidson H, Desai N. Interprofessional 
education between medical students and nurse practitioner students in a Global Health course. BMC Med Educ. 2018;18(1):200.

11. Homeyer S, Hoffmann W, Hingst P, Oppermann RF, Dreier-Wolfgramm A. Effects of interprofessional education for medical and nursing students: enablers, barriers and expectations for optimizing future interprofessional collaboration: a qualitative study. BMC Nurs. 2018;17:13.

12. Račić M, Joksimović BN, Cicmil S, et al. The effects of interprofessional diabetes education on the knowledge of medical, dentistry and nursing students. Acta Med Acad. 2017;46(2):145-154.

13. Lin YC, Chan TF, Lai CS, Chin CC, Chou FH, Lin HJ. The impact of an interprofessional problem-based learning curriculum of clinical ethics on medical and nursing students' attitudes and ability of interprofessional collaboration: a pilot study. Kaohsiung J Med Sci. 2013; 29(9):505-511.

14. Berger S, Mahler C, Krug K, Szecsenyi J, Schultz JH. Evaluation of interprofessional education: lessons learned through the development and implementation of an interprofessional seminar on team communication for undergraduate health care students in Heidelberg: a project report. GMS J Med Educ. 2016;33(2):Doc22.

15. Reeves S, Perrier L, Goldman J, Freeth D, Zwarenstein M. Interprofessional education: effects on professional practice and healthcare outcomes (update). Cochrane Database Syst Rev. 2013;2013(3):CD002213.

16. World Health Organization. WHO patient safety curriculum guide for medical schools. http://apps.who.int/ iris/handle/10665/44091. Published 2009. Accessed November 20, 2019.

17. Meng AL, Sullivan J. Interactive theater: an innovative conflict resolution teaching methodology. J Nurses Staff Dev. $2011 ; 27(2): 65-68$.

18. Kirkpatrick D, Kirkpatrick J. Evaluating training programs: the four levels. San Francisco, USA: BerrettKoehler Publishers; 1994.

19. Norris J, Carpenter JG, Eaton J, et al. The development and validation of the Interprofessional Attitudes Scale: assessing the interprofessional attitudes of students in the health professions. Acad Med. 2015;90(10):1394-1400.

20. Park KH, Park KH, Kwon OY, Kang Y. A validity study of the Korean version of the interprofessional attitudes scale. Korean Med Educ Rev. 2020;22(2):122-130.

21. Mann K, McFetridge-Durdle J, Breau L, et al. Development of a scale to measure health professions students' self-efficacy beliefs in interprofessional learning. J Interprof Care. 2012;26(2):92-99.

22. Kwon OY, Park KH, Park KH, Kang Y. Validity of the self-efficacy for interprofessional experimental learning scale in Korea. Korean Med Educ Rev. 2019;21(3): 155-161.

23. Khalili H, Orchard C, Laschinger HK, Farah R. An interprofessional socialization framework for developing an interprofessional identity among health professions students. J Interprof Care. 2013;27(6):448-453.

24. Kim SJ, Kwon OD, Kim $\mathrm{KH}$, et al. Investigating the effects of interprofessional communication education for medical students. Korean J Med Educ. 2019;31(2): 135-145. 